\title{
Analysis of the film thickness of a root canal sealer following three obturation techniques
}

\section{Análise da espessura da linha de cimento endodôntico em três técnicas de obturação}

\author{
Gustavo André De Deus* \\ Fábio Martins** \\ Ana Carolina Machado Rocha Lima** \\ Eduardo Diogo Gurgel-Filho*** \\ Claudio Ferreira Maniglia**** \\ Tauby Coutinho-Filho*****
}

\begin{abstract}
The aim of this study was to obtain a quantitative analysis of the film thickness of a root canal sealer formed after filling by three different techniques. Thirty human maxillary incisors were selected and access cavities were prepared using high-speed diamond stones and water spray. A size \#15 K-Flexofile was introduced in the canal of each specimen until it was seen just at the apical foramen. The working length was determined to be $1 \mathrm{~mm}$ short of that position and the canals were prepared to an apical size of \#45 K-Flexofile. Copious irrigation with $5.25 \% \mathrm{NaOCl}$ (sodium hypochlorite) was used during and after instrumentation. The samples were divided into three groups and obturated as follows: G1 - lateral condensation, G2 - lateral condensation with an accessory cone, and G3 - continuous wave of condensation. The samples were evaluated in the cervical, middle and apical thirds. The film thickness of the root canal sealer was measured through a microscopic evaluation. Statistical analysis was obtained using the Wilcox test. Statistical analysis showed significant differences between G3 and G1, G3 and G2 (p $\leq 0.05$ ). In general, the lowest film thickness was observed in the continuous wave of condensation (G3). Lateral condensation with an accessory cone (G2) and lateral condensation (G1) demonstrated poorer results in this study, showing a higher film thickness. The small film thickness of the sealer obtained by the continuous wave of condensation technique may increase the clinical performance of this technique.
\end{abstract}

DESCRIPTORS: Dental cements; Endodontics; Root canal obturation; Root canal therapy.

\begin{abstract}
RESUMO: O objetivo deste estudo foi realizar uma análise quantitativa da espessura da linha de cimento endodôntico formada por três técnicas de obturação. Trinta incisivos centrais superiores humanos foram selecionados e acessados de modo convencional. Uma lima $\mathrm{n}^{\circ} 15 \mathrm{~K}$-Flexofile foi usada para a verificação da patência foraminal e para determinação do comprimento de trabalho, que foi estabelecido a $1 \mathrm{~mm}$ aquém do forame apical. Os canais foram preparados até a lima $n^{\circ} 45$. Hipoclorito de sódio a $5,25 \%$ foi usado durante toda a instrumentação. Os dentes foram divididos em 3 grupos e obturados pelos seguintes critérios: G1 - condensação lateral; G2 - compressão hidraúlica e G3 - onda de condensação. Os dentes foram seccionados e analisados nos terços cervical, médio e apical. A espessura do filme de cimento foi determinada por um processo semi-automático de análise e processamento digital de imagens realizado no software KS 400. O tratamento estatístico foi realizado com teste de Wilcox, que revelou diferenças significantes entre G3 e G1 e entre G3 e G2, sendo p $\leq$ 0,05. Não houve diferenças estatisticamente significantes entre G1 e G2. De um modo geral, a compressão hidraúlica (G2) e condensação lateral (G1) revelaram uma maior espessura do filme de cimento. A menor espessura do filme de cimento obtida pela técnica de onda de condensação tende a melhorar a performance clínica dessa técnica em relação às outras testadas.
\end{abstract}

DESCRITORES: Cimentos dentários; Endodontia; Obturação do canal radicular; Tratamento do canal radicular.

\section{INTRODUCTION}

Although gutta-percha is not considered an ideal filling material, it still represents the first choice for a solid core filling for the root canal system, producing the best clinical performance when associated to a root canal sealer ${ }^{2,5}$. The excellent results, however, have not prevented the binomial gutta-percha/sealer from the constant questioning concerning the filling's final quality, the capa-

* MSc.

** Specialized in Endodontics; *****PhD, Department of Endodontics, School of Dentistry, Rio de Janeiro State University.

$* * * \mathrm{PhD} ;{ }^{* * * *}$ Doctorate Student - Department of Endodontics, School of Dentistry, State University of Campinas. 
De Deus GA, Martins F, Lima ACMR, Gurgel-Filho ED, Maniglia CF, Coutinho-Filho T. Analysis of the film thickness of a root canal sealer following three obturation techniques. Pesqui Odontol Bras 2003;17(2):119-25.

city of lateral and apical sealing, leakage indexes and also its ability to promote a three dimensional filling.

Gutta-percha does not provide an apical seal to ink penetration when used without a root canal sealer $^{5,8}$. Upon this confirmation of the necessity of the presence of a root canal sealer, investigations about the performance of the sealer were conducted throughout the years. The physical properties of different canal sealers were analyzed and a strong tendency to increase their adhesiveness was observed during the 1970's ${ }^{12}$. It has also been confirmed that leakage may occur within the sealer or by its dissolution, either in the interface between sealer and dentine, or between sealer and the gutta-percha ${ }^{9}$. Another aspect to consider is that areas filled by a sealer are more vulnerable ${ }^{17}$. The presence of a root canal sealer, in any filling technique, reduces clinical leakage ${ }^{5,8}$. Moreover, the root canal sealer is capable of filling imperfections and increasing the adaptation of the gutta-percha filling. Although many studies have indicated the undeniable necessity of a root canal sealer, its confirmed solubility implies the necessity to limit its presence to a thin film thickness ${ }^{1,17}$. Sealer film thickness may be of particular relevance to conventional techniques that involve solid core fillings.

The aim of this study was to obtain a quantitative analysis of the film thickness of a root canal sealer formed after filling by three different techniques.

\section{MATERIALS AND METHODS}

For the present work, thirty maxillary central incisors were selected from the Tooth Bank of the Rio de Janeiro State University. Standard access cavities were made and the patency of each canal was confirmed by inserting a \#20 file through the apical foramen before and after completion of the root canal preparation. The working length was determined at $1 \mathrm{~mm}$ short of the apex and the canals were shaped manually using a crown-down technique and stainless steel Flexofiles ${ }^{\circledR}$ (Dentsply-Maillefer, Ballaigues, Switzerland) and Gates Glidden burs (\#6, \#5, \#4, \#3).

The coronal and middle thirds of each canal were preflared using Gates Glidden drills (Dentsply-Maillefer, Ballaigues, Switzerland), \#6, \#5, \#4 and \#3. The middle and apical thirds were prepared with Flexofiles ${ }^{\circledR}$ (Dentsply-Maillefer, Ballai- gues, Switzerland), \#60, \#55, \#50 and \#45 using a balanced force technique as described by Roane et $a l{ }^{16}, 1985$. The canals were irrigated between each file with $2 \mathrm{ml}$ of freshly prepared $5.25 \%$ solution of sodium hypochlorite using a syringe and 27-gauge needle. All the teeth received a final flush of $10 \mathrm{ml}$ of $17 \%$ EDTA (pH 7.7) (Biodinâmica, Ibiporã, PR, Brazil) followed by $10 \mathrm{ml}$ of $5.25 \%$ sodium hypochlorite to remove the smear layer ${ }^{23}$.

The 30 teeth were randomly divided into three equal groups and obturated as follows: Group 1: lateral condensation technique; Group 2: lateral condensation technique with an accessory cone ${ }^{4}$, and Group 3: warm gutta-percha condensation technique e,10,17,18,19 combined with the Obtura II System (Obtura Corp., Fenton, MO, USA) in the backfilling phase (i.e. continuous wave of condensation).

A zinc-oxide eugenol sealer (Endofill, Dentsply, Petrópolis, RJ, Brazil) was mixed manually according to the recommendations of the manufacturer and used for all groups. A \#40 file was used to pick up the measured spoon of sealer $(0.25 \mathrm{ml})$ two times from the mixing pad and placed into the canal whilst rotating it counterclockwise.

In the lateral condensation group (G1), a \#45 master gutta-percha cone (Diadent Group International, Chongchong Buk Do, Korea) was coated with a measured spoon of sealer $(0.25 \mathrm{ml})$ and placed in the canal to the full working length. Lateral compaction was achieved in each canal by using accessory MF gutta-percha cones (medium fine) (Dentsply-Maillefer, Ballaigues, Switzerland) and the endodontic finger spreader size B (DentsplyMaillefer, Ballaigues, Switzerland). A heated instrument was used to remove the excess guttapercha.

In the lateral condensation with an accessory cone (G2), the tip of a medium sized non-standardized gutta-percha cone with a 0.6 taper (Diadent Group International, Chongchong Buk Do, Korea) was trimmed back until tug-back was achieved in the full working length. The trimmed gutta-percha cone was coated with a measured spoon of sealer $(0.25 \mathrm{ml})$. A heated instrument was used to remove the excess gutta-percha and then vertical force was applied with a plugger $(1.0 \mathrm{~mm}$, Dentsply-Maillefer, Ballaigues, Switzerland) to compact the gutta-percha in the coronal third of the canal ${ }^{4,17}$.

In the warm gutta-percha group (G3), the tip of a medium sized non-standardized gutta-percha 
De Deus GA, Martins F, Lima ACMR, Gurgel-Filho ED, Maniglia CF, Coutinho-Filho T. Analysis of the film thickness of a root canal sealer following three obturation techniques. Pesqui Odontol Bras 2003;17(2):119-25.

cone with a 0.6 taper (Diadent Group International, Chongchong Buk Do, Korea) was trimmed back until tug-back was achieved in the full working length. The trimmed gutta-percha cone was coated with a measured spoon of sealer $(0.25 \mathrm{ml})$. At the level of the cementum-enamel junction the gutta-percha was scared off with the tip an activated heat carrier (Touch'n Heat model 5004, Analytic Technology, Redmond, WA, USA). After deactivating the heat carrier, the cooling instrument was removed from the canal, bringing out an increment of gutta-percha. Vertical force was applied with a size 11 plugger $(1.1 \mathrm{~mm}$ diameter, Dentsply-Maillefer, Ballaigues, Switzerland) to compact the gutta-percha in the coronal third of the canal. This procedure was repeated twice, first to a level 3-4 mm deeper than the cementum-enamel junction and vertically condensing the gutta-percha in the middle third of the canal using a size 7 plugger (0.7 $\mathrm{mm}$ diameter, Dentsply-Maillefer, Ballaigues, Switzerland), and secondly to a level $4 \mathrm{~mm}$ short of the full working length and vertically condensing the gutta-percha in the apical portion of the canal using a size 5 plugger $(0.5 \mathrm{~mm}$ diameter, Dentsply-Maillefer, Ballaigues, Switzerland). Back-filling of the rest of the canal space was achieved by injecting warm gutta-percha using the Obtura II System (Obtura Corp., Fenton, MO, USA), each time injecting a 4-5 $\mathrm{mm}$ segment and condensing the gutta-percha with a prefitted plugger $^{3,17,18,19}$.

The samples were then stored in 100\% humidity and at $37^{\circ} \mathrm{C}$ for 2 weeks. After that, each sample was sectioned longitudinally using a low-speed saw (Isomet, Buhler Ltd., Lake Bluff, NY, USA) with a diamond disc $(\varnothing 125 \mathrm{~mm} \times 0,35 \mathrm{~mm} \times$ $12,7 \mathrm{~mm}$ - model 330C) while constantly irrigating with water in order to prevent overheating. The cuts were made in different points: one located at the cervical third, the other two at the middle and apical thirds respectively. Subsequently, the samples were embedded in an epoxy resin cylinder (Arazyn 1.0, Ara Química, SP, Brazil) to facilitate their manipulation and improve the preparation result. The margins adjoining the epoxy resin and tooth were sealed with cyanoacrylate (Super Bonder gel, Loctite, Itapevi, SP, Brazil).

Specific sandpapering (NETOT 4050014, Struers, DK) for materialographic preparation was performed. The purpose of materialographic specimen preparation is to obtain a surface that is free from scratches and deformation. To achieve this result the samples were properly ground to remove damages or deformed surface material, while introducing as little new deformation as possible, thus preparing the sample surface for polishing. To remove deformations from fine grinding and obtain a surface that is highly reflective, the specimens were polished before they were examined under the microscope. Polishing was accomplished with diamond paste with 4-1 $\mu \mathrm{m}$ roughness (SAPUQ 40600235, Struers, DK).

The samples were examined under a microscope (Axiscope, Carl Zeiss Vision Gmbh, Hallbergmoos, Germany). For each sample, a sequence of photographs with increases of $50 \mathrm{X}$ and $200 \mathrm{X}$ was taken, the dentinal wall/filling material interface being always the observation focus. The negatives were scanned by a $35 \mathrm{~mm} /$ medium format film scanner (SprintScan 120, Polaroide, NY, USA) as tiff images (tagged image file format) with 1,200 dpi.

For image analysis and processing, the KS 400 Image System 4.0 (Carl Zeiss Vision Gmbh, Hallbergmoos, Germany) was used. Through a segmentation process on pixels shade of digitized image, the software allowed us, by a semi-automated process, to obtain measurements made in areas with higher film thickness of the root canal sealer. In order to rationalize and automate the work, a protocol (macro) was developed and used to analyze all images.

Through this digital image analysis and processing by the KS 400 Image System 4.0 (Carl Zeiss Vision Gmbh, Hallbergmoos, Germany), about 20 measurements for each observed field examined were obtained. A Wilcox test was used to determine whether there were significant differences between the groups.

\section{RESULTS}

With the aid of the digital analysis and processing imaging, numerical data were obtained from the measurements performed. The data obtained from the apical, middle and cervical cross-sections, and a general average for each technique, are displayed in Graphs 1 and 2. Statistical analysis was obtained using the Wilcox test (Table 1).

\section{Cervical third}

The evaluation of the cuts obtained from the cervical thirds in the samples demonstrated a gre- 
De Deus GA, Martins F, Lima ACMR, Gurgel-Filho ED, Maniglia CF, Coutinho-Filho T. Analysis of the film thickness of a root canal sealer following three obturation techniques. Pesqui Odontol Bras 2003;17(2):119-25.

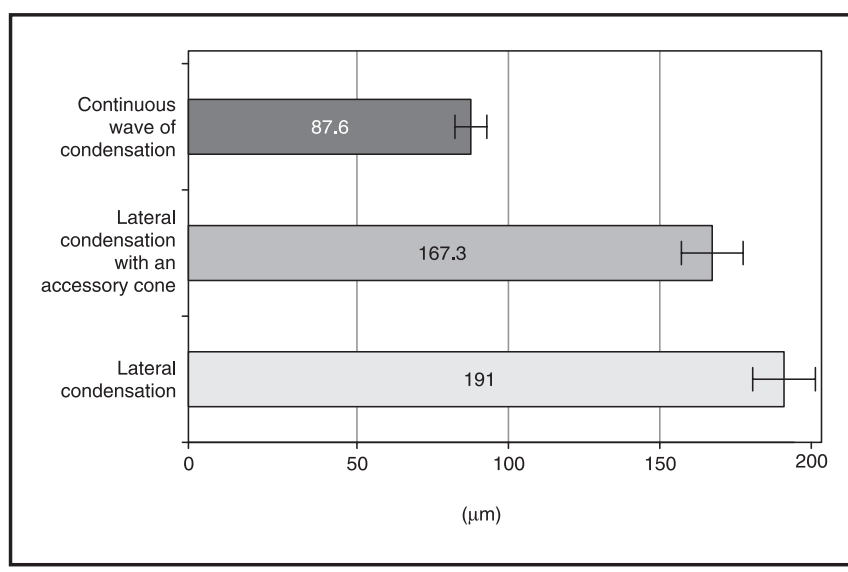

GRAPH 1 - General average of film thickness of sealer in each technique analyzed.

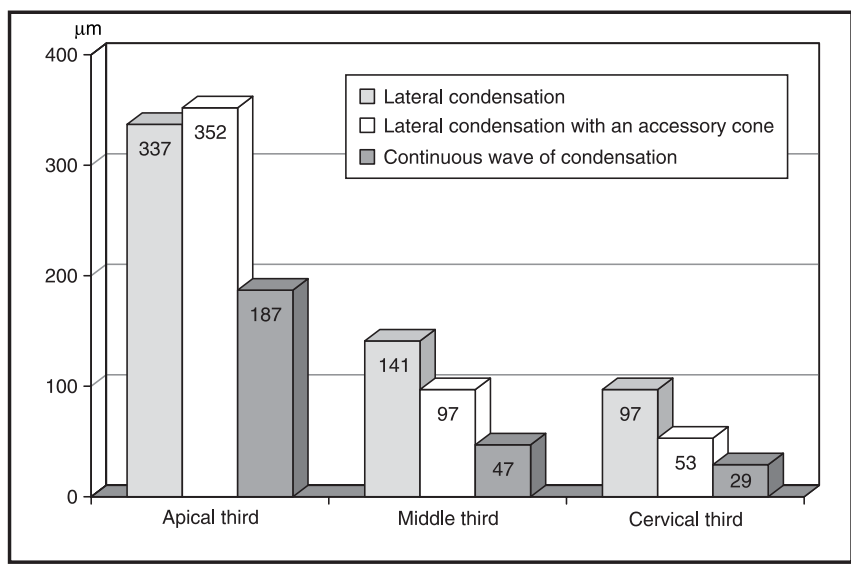

GRAPH 2 - Average of film thickness of sealer at third analyzed.

TABLE 1 - Wilcox test for significant differences for sealer film thickness in different thirds (ns: not significant, s: significant).

\begin{tabular}{|c|c|c|c|}
\hline & Apical & Middle & Cervical \\
\hline $\begin{array}{l}\text { Lateral condensation } \\
v s . \text { lateral condensa- } \\
\text { tion with an accessory } \\
\text { cone }\end{array}$ & $\begin{array}{c}\mathrm{ns} \\
(\mathrm{p}>0.05)\end{array}$ & $\begin{array}{c}\mathrm{s} \\
(\mathrm{p} \leq 0.05)\end{array}$ & $\begin{array}{c}\mathrm{s} \\
(\mathrm{p} \leq 0.05)\end{array}$ \\
\hline $\begin{array}{l}\text { Lateral condensation } \\
v s \text {. continuous wave } \\
\text { of condensation }\end{array}$ & $\begin{array}{c}\mathrm{s} \\
(\mathrm{p} \leq 0.05)\end{array}$ & $\begin{array}{c}\mathrm{s} \\
(\mathrm{p} \leq 0.05)\end{array}$ & $\begin{array}{c}\mathrm{s} \\
(\mathrm{p} \leq 0.05)\end{array}$ \\
\hline $\begin{array}{l}\text { Lateral condensation } \\
\text { with an accessory } \\
\text { cone } v s \text {. continuous } \\
\text { wave of condensation }\end{array}$ & $\begin{array}{c}\mathrm{s} \\
(\mathrm{p} \leq 0.05)\end{array}$ & $\begin{array}{c}\mathrm{s} \\
(\mathrm{p} \leq 0.05)\end{array}$ & $\begin{array}{c}\mathrm{s} \\
(\mathrm{p} \leq 0.05)\end{array}$ \\
\hline
\end{tabular}

at lack of homogeneity of the filling material in all techniques. Particularly in this area it was possi- ble to observe smaller layers of root canal sealer (Figures 1 and 2). The results revealed film thickness varying from 15 to $101 \mu \mathrm{m}$, presenting an average post of $29 \mu \mathrm{m}$ for Group 3, $53 \mu \mathrm{m}$ for Group 2 and $97 \mu \mathrm{m}$ for Group 1. The statistical analysis demonstrated significant differences between groups $(\mathrm{p} \leq 0.05)$.

\section{Middle third}

In the same manner as for the cervical third, the analysis of the performed cuts of the middle third samples demonstrated a generalized lack of homogeneity of filling material in all techniques (Figure 3). Group 1 clearly confirmed a greater presence of root canal sealer. The measurements revealed layers of root canal sealer varying between 30 and $161 \mu \mathrm{m}$, presenting an average post of $47 \mu \mathrm{m}$ for Group 3, $97 \mu \mathrm{m}$ for Group 2 and $141 \mu \mathrm{m}$ for Group 1. Statistical analysis established significant difference between the groups $(p \leq 0.05)$.

\section{Apical third}

The observation of samples obtained in this area demonstrated the greatest quantities of root canal sealers in all techniques (Figure 4). Measurements revealed sealer layers with thickness varying between 121 and $399 \mu \mathrm{m}$, obtaining an average post of $337 \mu \mathrm{m}$ for Group 1, $352 \mu \mathrm{m}$ for Group 2 and $187 \mu \mathrm{m}$ for Group 3. There was no statistical difference between Group 1 and 2 ( $p>0.05)$. However, statistically significant difference was observed for Group 3 in relation to the previous groups $(\mathrm{p} \leq 0.05)$.

\section{DISCUSSION}

A fundamental factor for this study is the fact that a thin film thickness sealer should be expected to wet the surface better than a thick film thickness sealer and thus provide a better se$\mathrm{al}^{7,15,17}$. This study was based on the necessity to carry out a technique that reduces this material to a small layer. Many authors documented the imperative utilization of a root canal sealer and its fundamental requirements ${ }^{17}$. Grossman ${ }^{6}$ (1981) and other authors ${ }^{9,12,21}$ observed a diversity of characteristics, including solubility, flow, setting time, power of compression, radiopacity, and adhesion properties of the root canal sealers. With the introduction of warm gutta-percha techniques, authors have emphasized the necessity to reexamine the 
De Deus GA, Martins F, Lima ACMR, Gurgel-Filho ED, Maniglia CF, Coutinho-Filho T. Analysis of the film thickness of a root canal sealer following three obturation techniques. Pesqui Odontol Bras 2003;17(2):119-25.

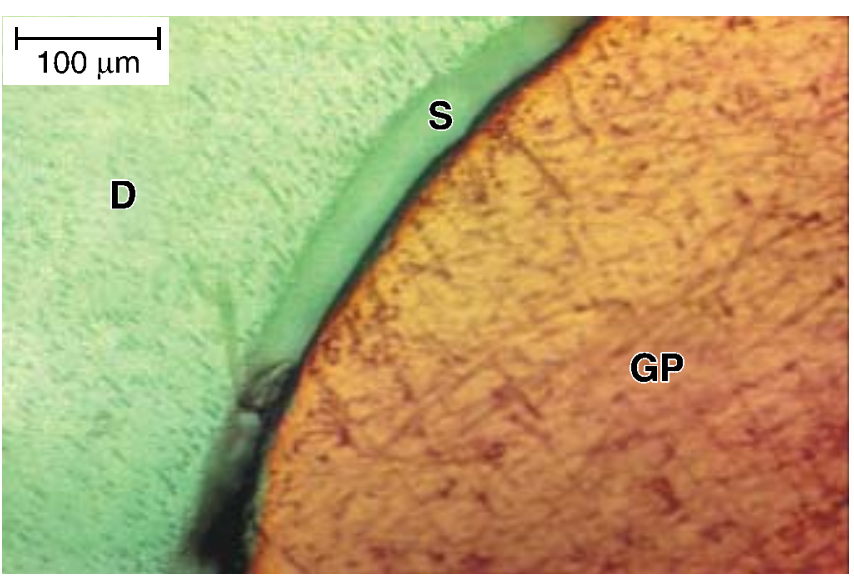

FIGURE 1 - Cross-section of cervical third showing a thin layer of sealer (S), in interface between filling (GP) and dentinal wall (D). Continuous wave of condensation technique, $200 \mathrm{X}$.

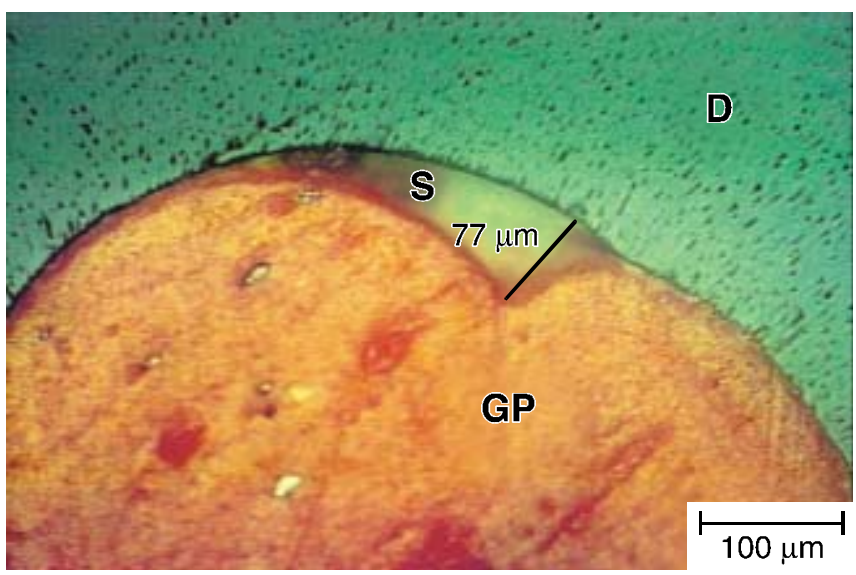

FIGURE 3 - Cross-section of middle third showing a film thickness of sealer (S) with $77 \mu \mathrm{m}$. Interface between gutta-percha (GP) and dentinal wall (D). Lateral condensation with an accessory cone, $200 \mathrm{X}$.

influence of the film thickness of the sealer towards the apical sealing produced by the filling material ${ }^{1,11,13,14,22}$.

The analysis of the samples in this study showed that the thickness of the layer of the sealer in an interface between filling and the dentinal walls varied both according to the groups and to the analyzed cross-sections. As expected, results presented variation in the film thickness within the same sample, due to areas partially instrumented or areas with accumulation of debris.

The lack of mass uniformity, the compromised juxtaposition of the gutta-percha/sealer and dentinal walls unit and the greater extension of the root canal sealer interface were reflected in the

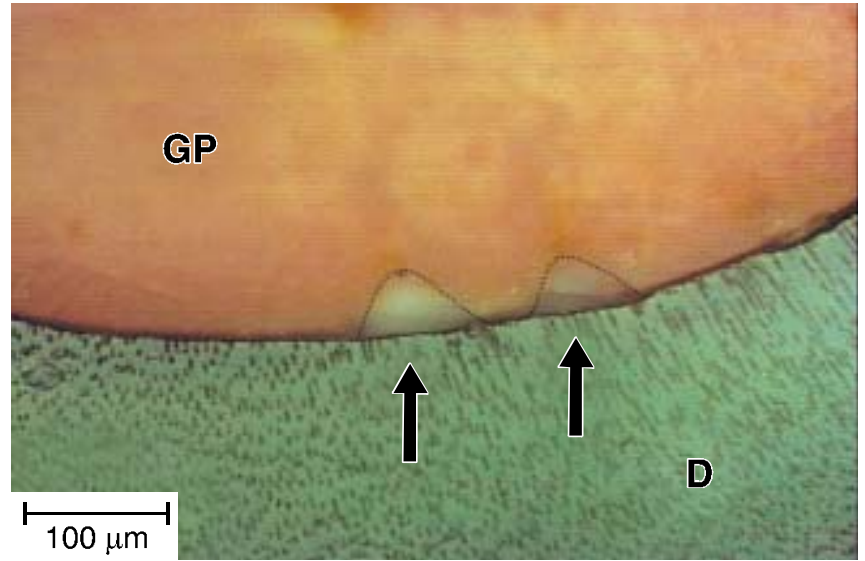

FIGURE 2 - Cross-section of cervical third showing a close adaptation of gutta-percha (GP) to dentinal wall (D). The arrows indicate a lack of gutta-percha.

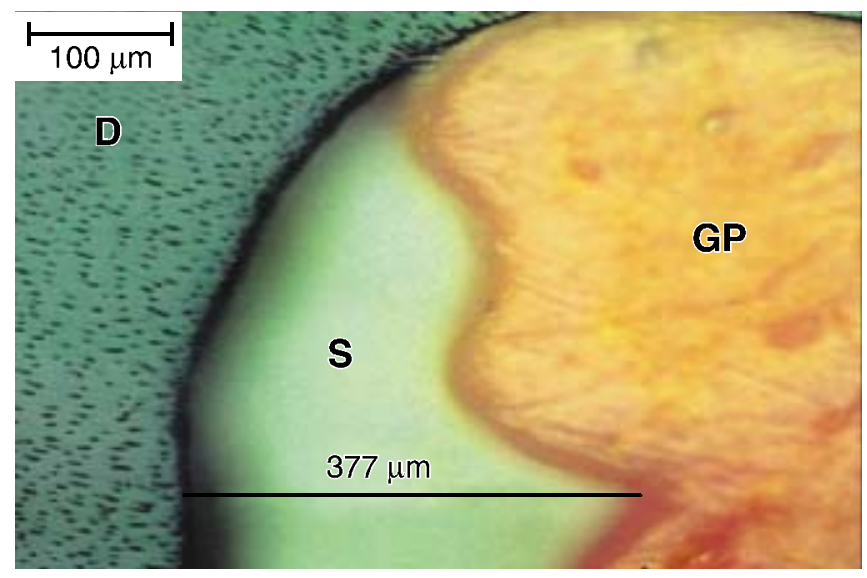

FIGURE 4 - Cross-section of apical third showing the highest film thickness of sealer (S) followed in this study $(337 \mu \mathrm{m})$. Interface between gutta-percha (GP) and dentinal wall (D). Lateral condensation, $200 \mathrm{X}$.

analyses of samples in Group 1 and also Group 2, though in a smaller intensity. For the hydraulic compression and warm gutta-percha (Groups 2 and 3), a non-standardized medium cone with a 0.6 taper, which presents greater taper than the standardized cones, was used as the master co$\mathrm{ne}^{3,4,14,17}$. The smaller layer of the root canal sealer at the cervical and middle thirds can be used to explain superior adaptation of the medium large accessory cone to the conical pattern of the canal preparation $^{4,14,17}$.

Void areas were frequently observed in Group 1. This is evidence for a greater susceptibility of this group to leakage. This is also supported by studies that reaffirm the great importance of a 
De Deus GA, Martins F, Lima ACMR, Gurgel-Filho ED, Maniglia CF, Coutinho-Filho T. Analysis of the film thickness of a root canal sealer following three obturation techniques. Pesqui Odontol Bras 2003;17(2):119-25.

root canal sealer. In an experiment performed by Hata et al. ${ }^{8}$ (1992) for example, the authors indicated that the lack of sealer interface would result in a greater marginal leakage in their samples. Among such investigations, Bamiduro et al. ${ }^{1}$ (1992) tested the hypothesis that an apical sealing promoted by thermoplasticized gutta-percha techniques depends on the thickness of the layer of the root canal sealer. The degree of microleakage was based on the depth of ink penetration at the apical third.

In our study, the samples from Group 3 (warm gutta-percha condensation technique) presented a smaller interface of root canal sealer, and the presence of such unfulfilled spaces by the sealer was significantly smaller. Gutta-percha, after being heated, is plasticized from 3 to $5 \mathrm{~mm}$ from its heating locus. After heating, dynamic vertical condensation is performed, in a technique known as warm gutta-percha ${ }^{3}$. This dynamic process of heating and condensing must end $5 \mathrm{~mm}$ from the apex ${ }^{17}$. The warm gutta-percha technique, when evaluated by scanning electron microscopy, demonstrated a very close adaptation between dentinal wall, sealer, and gutta-percha ${ }^{20}$. At the deepest point of penetration, $3 \mathrm{~mm}$ from the apex, a wall-to-wall adaptation was observed. The film thickness of sealer ranged from 40 to $100 \mu \mathrm{m}^{10}$. Our results pre-

\section{REFERENCES}

1. Bamiduro R, Ogtenbi G, Shen O. Effect of different sealers on thermoplasticized gutta-percha root canal obturations. J Endod 1992;18:363-6.

2. Brayton S, Davis S, Goldman M. Gutta-percha root canal fillings. Oral Surg Oral Med Oral Pathol 1973;35:226-31.

3. Buchanan LS. The continuous wave of obturation technique: 'centered' condensation of warm gutta-percha in 12 seconds. Dent Today 1996;15:60-2,64-7.

4. De Deus QD. Endodontia. $5^{\text {th }}$ ed. Rio de Janeiro: Medsi; 1992.

5. Evans J, Simon J. Evaluation of the apical seal produced by injected thermoplasticized gutta-percha in the absence of smear layer and root canal sealer. J Endod 1986; 12:101-7.

6. Grossman LI. Endodontic practice. $10^{\text {th }}$ ed. Philadelphia: Lea \& Febiger; 1981.

7. Gutmann L. Adaptation of injected thermoplasticized gutta-percha in the absence of the dentinal smear layer. Int Endod J 1993; 26:87-9.

8. Hata I, Kawazoe S, Toda T, Weine F. Sealing ability of thermafil with or without sealer. J Endod 1992;18:322-36.

9. Hovland J, Dumsha C. Leakage evaluation in vitro of the root canal sealer cement Sealapex. Int Endod J 1985; 18:179-82. sented a greater interval of 15 to $200 \mu \mathrm{m}$ for the warm gutta-percha condensation technique, which nevertheless offered the best results in all three areas analyzed. It has been shown that deviations, undercuts, projections and resorptions many times disable the contact of the instrument to the dentinal walls, creating imperfections in the following filling procedure, especially in Group 1 and 2. On the other hand, considering the homogeneity factor, samples in Group 3 demonstrated a small incidence of voids, maybe because it promotes a higher degree of compaction of gutta-percha cones ${ }^{7}$.

\section{CONCLUSIONS}

The continuous wave of condensation promoted the lowest film thickness, which may increase the clinical performance of this technique.

\section{ACKNOWLEDGEMENTS}

The authors thank the Department of Science and Engineering of Materials (DCMM), Pontifical Catholic University of Rio de Janeiro (PUC-RJ), for the essential technical assistance in this study, especially in memorian to Eng. Maria de Fátima Lopes.

10. Lifshitz J, Schilder H, Pameijer C. Scanning electron microscope study of the warm gutta-percha technique. J Endod 1983;19:17-24.

11. Maniglia CA, Biffi JC, Carvalho L. Aspecto da guta-percha após a obturação pela técnica da condensação lateral e ultra-sônica. Rev Assoc Paul Cirur Dent 1997;51:69-74.

12. Mc Comb D, Smith C. Comparison of the physical properties of polycarboxilate base and conventional root canal sealers. J Endod 1976;3:228-35.

13. Michanowicz M, Andrew E, Nicholas P. Low-temperature $\left(70^{\circ} \mathrm{C}\right)$ injection gutta-percha: a scanning electron microscopic investigation. J Endod 1986;12:64-7.

14. Nguyen N. Filling root canals. In: Cohen S, Burns R. Pathways of the pulp. $6^{\text {th }}$ ed. Missouri: Mosby; 1994. p.219-71.

15. Orstavik D. Seating of gutta-percha points: effects of sealers with varying film thickness. J Endod 1982;8:213-8.

16. Roane JB, Sabala CL, Ducanson MG. The "balanced force" concept for instrumentation of curved canals. J Endod 1985;11:203-9.

17. Ruddle C. Filling root canals. In: Cohen S, Burns R. Pathways of the pulp. $7^{\text {th }}$ ed. Missouri: Mosby; 1994. p.285-7.

18. Schilder H. Filling root canals in three dimensions. Dent Clin North Am 1967 Nov;723-44. 
De Deus GA, Martins F, Lima ACMR, Gurgel-Filho ED, Maniglia CF, Coutinho-Filho T. Analysis of the film thickness of a root canal sealer following three obturation techniques. Pesqui Odontol Bras 2003;17(2):119-25.

19. Schilder H. Vertical compaction of warm gutta-percha. In: Gerstein H. Techniques in clinical endodontics. Philadelphia: WB Saunders; 1983. p.76-98.

20. Torabinejad M. Scanning electron microscopic study of root canal obturation using thermoplasticized gutta-percha. J Endod 1978;4:245-50.

21. Walton RE, Torabinejad M. Principles and practice of Endodontics. $2^{\text {nd }}$ ed. Philadelphia: Saunders; 1996.
22. Weller R, Kimbrough F, Anderson R. A comparison of thermoplastic obturation techniques: adaptation to the canal walls. J Endod 1997;23:703-6.

23. Yamada RS, Armas A, Goldman M, Lin PS. A scanning electron microscopic comparison of a high volume final flush with several irrigating solutions: Part 3. J Endod 1983; 9:137-42.
Recebido para publicação em 02/10/02

Enviado para reformulação em 10/03/03

Aceito para publicação em 15/05/03 